compensate for this by having repeated pregnancies. ${ }^{17}$ As explained above, such women would be unlikely to book for delivery at home. Similar selective forces probably explain the low perinatal mortality from congenital abnormalities among those booked for delivery at home.

Women who had a planned home delivery were a select group for social as well as medical reasons. They were concentrated in the higher social classes and in the 25-34 year age group, both of which are associated with favourable outcomes of pregnancy. The $5 \%$ of women who were booked for a hospital delivery but probably intended to have a birth at home may have been unable to book for a home delivery because they possessed one or more characteristics considered to make them unsuitable candidates. Although the results of our survey cover one year, the information derived from it suggests that over the period 1975-9 perinatal mortality among births at home declined at about the same rate as that among all births ( $\mathrm{R}$ Campbell, $\mathrm{PhD}$ thesis in preparation).

The perinatal mortality of $4 \cdot 1 / 1000$ births does not represent a true risk of perinatal death for babies born to women who planned to give birth at home. It does not take into account the women who intended to give birth at home but were transferred into hospital after the onset of labour. When the supervisors of midwives were contacted about the survey they were also asked about such women. Although most did not have this information readily accessible, the available data suggested that about $10 \%$ of women were transferred to hospital during labour. This figure is broadly consistent with that from other reports. ${ }^{18-22}$ Estimates of the risk of perinatal death for those transferring in labour are scarce, but the data from one health district included in our survey, and from other studies, ${ }^{8-22}$ although based on small numbers, suggest that the overall perinatal mortality could be as much as doubled when transfers in labour are accounted for. Thus if transfers had been included the perinatal mortality for all deliveries booked at home may have doubled to about $8 / 1000$, which is still below the national figure of $14 \cdot 6 / 1000$.

We thank the midwives for working so hard to complete the questionnaires; all staff of the Office of Population Censuses and
Surveys who helped with the project; Iain Chalmers and colleagues at the National Perinatal Epidemiology Unit; and Helen Edwards for secretarial help. RC was in receipt of a Medical Research Council $\subset$ research studentship, and AM was funded by the Department of $\widehat{\widehat{O}}$ Health and Social Security, which also met the cost of printing and distributing the questionnaires.

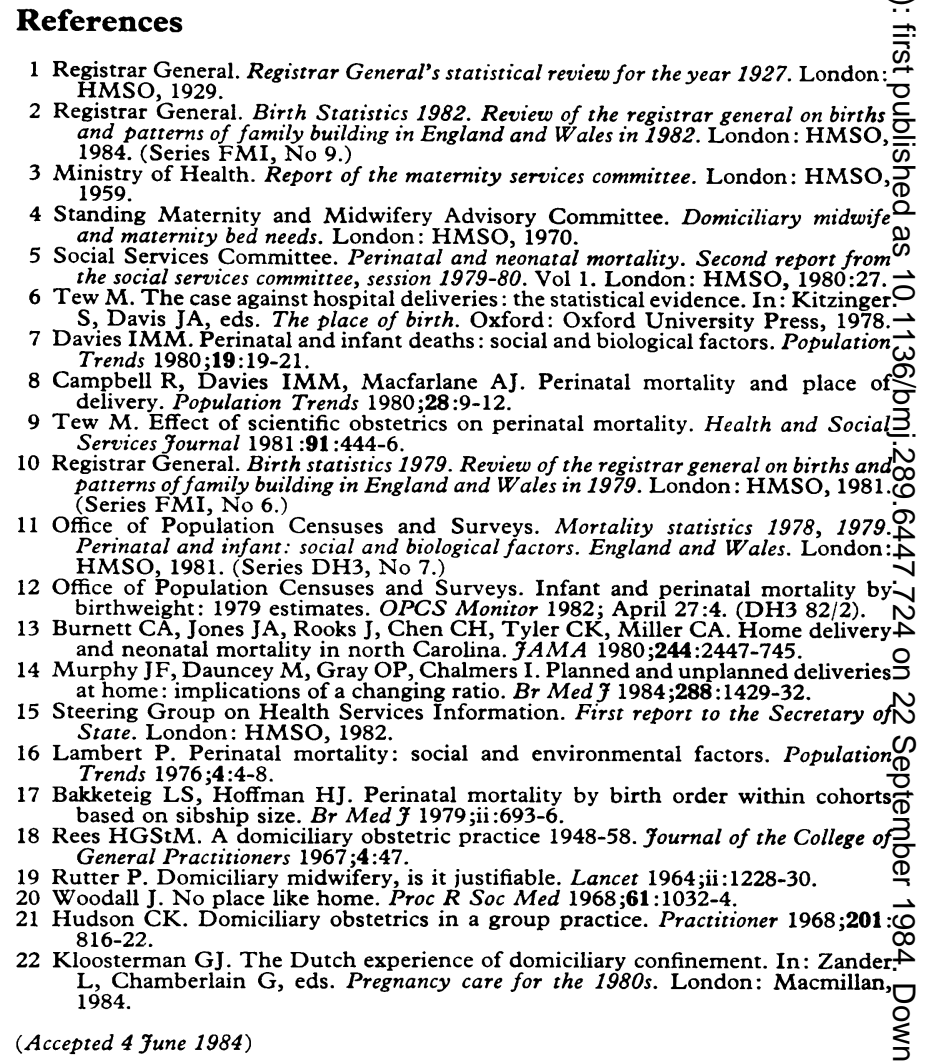

(Accepted 4 fune 1984)

\title{
Normal erythrocyte sedimentation rate in the elderly
}

\author{
R A GRIFFITHS, W R GOOD, N P WATSON, H F O’DONNELL, P J FELL, J M SHAKESPEARE
}

\begin{abstract}
Two hundred subjects aged $60-89$ were selected for a study aimed at defining a reference range for the erythrocyte sedimentation rate in the elderly. The study extended a previous survey in subjects aged 20-65.

The results confirmed that the sedimentation rate increases with age and that women have higher values than men but suggested that over half of elderly patients
\end{abstract}

Radcliffe Infirmary, Oxford OX2 6HE

R A GRIFFITHS, FRCP, consultant physician (geriatric medicine) W R GOOD, MA, MIBIOL, research officer

The Health Centre, Deddington, Oxon

N P WATSON, MB, CHB, family practitioner (principal) H F O'DONNELL, MB, BS, family practitioner (principal) P J FELL, MD, family practitioner (principal)

J M SHAKESPEARE, BM, MRCP, family practitioner (principal)

Correspondence and requests for reprints to: $\mathrm{Dr} \mathrm{R}$ A Griffiths. with disease would have rates within the previously? defined "normal" range.

It is therefore suggested that an erythrocyte sedimentation rate exceeding $19 \mathrm{~mm}$ in the first hour in elderly men and $22 \mathrm{~mm}$ in the first hour in elderly women? warrants investigation.

\section{Introduction}

The normal erythrocyte sedimentation rate in the elderly has been quoted as 3-50 mm in the first hour. ${ }^{1}$ Surveys of published? work show considerable variation, women having higher values $[0$ than men and both having an age related increase to 90 years. ${ }^{2}{ }^{3}$ The "normal" range has been variously described in $90 \%, 95 \%, \stackrel{\mathbb{D}}{\Omega}$ and $98 \%$ of asymptomatic subjects studied. ${ }^{425}$ While we might $\stackrel{\mathbb{Q}}{\mathscr{Q}}$ accept that values outside these ranges indicate pathologicalo change, we cannot state with certainty that a value within the "normal" range indicates absence of disease: there are at leasto two populations, normal and diseased, whose values overlap. The multiple aetiological factors that determine the sedimentation 
rate militate against a Gaussian model for its distribution, and age related factors must also be considered.

In a study of 27912 subjects aged 20-65 Miller et al defined a normal range that differed for men and women and increased with age. ${ }^{5}$ The present study, of a smaller number of subjects, extends these data to the elderly.

\section{Subjects, methods, and results}

A stratified, structured, age and sex matched sample of 200 subjects (100 men, 100 women) aged 60-89 who were able to attend a rural community practice were seen as part of a larger study. Blood was taken at the health centre and sent to the local hospital the same day for full blood count, estimation of erythrocyte sedimentation rate (Westergren ${ }^{6}$ ), and measurement of urea and electrolyte concentrations.

Past and present medical diagnoses and blood pressures were recorded. Statistical tests were performed using the statistical package for the social sciences ${ }^{7}$ and the mark 9 update of that technique. ${ }^{8}$

The sedimentation rate in the sample was not normally distributed but the square root transform of the rate was acceptable ${ }^{9}$ and was used in the analysis.

The effects of diagnosed disease (autoimmune disorders, malignancy, pyelonephritis, chronic obstructive airways disease), raised white cell count, anaemia, and current drug treatment were estimated by analysis of covariance (statistical package for the social sciences program ANOVA) using the regression approach. Disease and raised white cell count were significantly correlated with raised sedimentation rate $(\mathrm{p}<0.01$ and $\mathrm{p}<0.005$ respectively); drug treatment was not. Decreased haemoglobin concentration was highly correlated with a raised sedimentation rate and with increasing age; these effects could not be separated statistically, and they were not extracted from subsequent analysis.

The effects of disease and raised white cell count were extracted from the relation of sedimentation rate with age by multiple regression (statistical package for the social sciences program Regression) to provide a simple description of the relation. The figure plots the mean and 98 th percentile of this relation for men and women after extraction of these effects; the interrupted line shows the relation predicted by the algorism of Miller et al.

\section{Comment}

This study confirms the general relation between erythrocyte sedimentation rate and age described by Miller et al in the 20-65 year age range ${ }^{5}$ and extends the range to 89 years. The figure shows data derived from our analysis and retransformed for comparison with the data of Miller et al. ${ }^{5}$

The algorism devised by Miller et al (sedimentation rate $=$ for men: age in years $\div 2$; for women: (age in years +10$) \div 2$ ) for the age range 20-65 years is also applicable to the age range 60-89. This predicted relation (see figure) provides an approximation to the $98 \%$ curves.

Miller et al presumed that the 98th percentile of the statistical distribution was an adequate definition of abnormality. This, however, may have minimal clinical relevance. ${ }^{10}$ The 98th percentile has value in indicating raised sedimentation rates that demand investigation. Rates below this may be normal; however, there are at least two populations (normal and diseased), whose rates overlap considerably. Many patients with diagnosed disease fall below the high definition of abnormality set by Miller et al. The figure plots the mean sedimentation rates of the subgroups of 23 men and 22 women with disease, diagnosed as above. The mean value for these patients fell well below the 98 th percentile. suggesting that at least half of diseased patients will have sedimentation rates below the limit defined by Miller et al. ${ }^{5}$ While the age relation in these small samples may not be dependable, it might reasonably be suggested that erythrocyte sedimentation rates above the grand mean of these impaired samples are worthy of further investigation. We suggest the mean values in these samples-namely, $19 \mathrm{~mm}$ in the first hour in elderly men and $22 \mathrm{~mm}$ in the first hour in elderly women-as more clinically relevant.

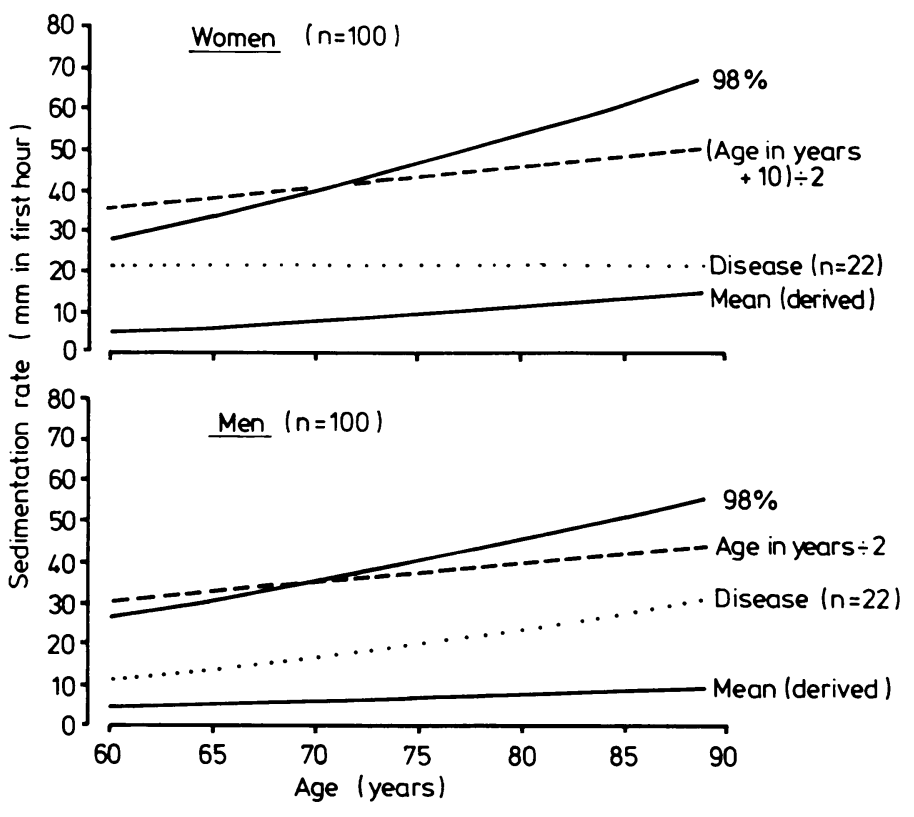

Erythrocyte sedimentation rates in men and women, with derived normalised values of mean and 98 th percentile. Interrupted line shows predicted algorism of Miller $e t a^{5}$ and dotted line is mean for subset of patients with disease.

We conclude that the algorisms of Miller et al for young patients approximately predict the 98th percentile of erythrocyte sedimentation rates in the elderly. Nevertheless, the sedimentation rate of many patients with disease falls below this limit. In our sample of elderly patients with disease, mean rates were $19 \mathrm{~mm}$ in the first hour in men and $22 \mathrm{~mm}$ in the first hour in women. Higher values certainly warrant investigation.

We thank the haematology laboratory of the Horton General Hospital, Banbury, for performing the haematological investigations, and $\mathrm{Dr}$ Paul Griffiths, of Oxford University, for helpful statistical comments. We also acknowledge the financial support of the Nuffield Foundation (RAG and WRG).

\section{References} 1 Hodkinson HM. Biochemical diagnosis of the elderly. London: Chapman and Hall,

2 Schapera $\dot{R}$. The significance of erythrocyte sedimentation rates in aged persons. $S$ Afr Med $\mathcal{F} 1982 ; 62: 394-6$.

3 Hyams DE. The blood. In: Brocklehurst JC, ed. Textbook of geriatric medicine and gerontology. 2nd ed. Edinburgh: Churchill Livingstone, 1978:567-9.

Gilbertsen VA. Erythrocyte sedimentation rates in older patients. A study of 4341 cases. Postgrad Med 1965;38:A44-52.

5 Miller A, Green M, Robinson D. Simple rule for calculating normal erythrocyte sedimentation rate. $B r M e d \mathcal{F} 1983 ; 286: 266$.

6 Dacie JV, Lewis SM. Practical haematology. 5th ed. Edinburgh: Churchill Livingstone, 1975:580-1.

7 Nie NH, Hull CH, Jenkins JG, Steinbrenner K, Bent DH. Statistical package for the social sciences. 2nd ed. New York: McGraw Hill, 1975.

$8 \mathrm{Nie} \mathrm{NH}$, Hull $\mathrm{CH}$. SPS S update 7-9: new procedures and facilities for releases 7-9. New York: McGraw Hill, 1981. Bowman $\mathrm{KO}$ Shenton $L R$. Omnibus test contours for departures from normality Eastham RD. Simple rule for calculating normal erythrocyte sedimentation rate.
Br Med $\mathcal{F}$ 1983;286:557-8.

(Accepted 9 fuly 1984) 